\title{
Construction validation of an instrument for nursing care related to cutaneous xerosis
}

\author{
Validação de constructo de um instrumento para os cuidados de enfermagem relacionados a xerose cutânea \\ Validación de constructo de un instrumento para los cuidados de enfermería relacionados a la xerosis cutánea
}

$\begin{array}{r}\hline \text { Ronny Anderson de Oliveira Cruz ' } \\ \text { ORCID: 0000-0001-6443-7779 } \\ \text { Thaynara Ferreira Filgueiras' } \\ \text { ORCID: 0000-0001-7520-4145 } \\ \text { Maria Auxiliadora Pereira' } \\ \text { ORCID: 0000-0002-0614-4051 } \\ \text { Glenda Agral' } \\ \text { ORCID: 0000-0002-7628-9029 } \\ \text { Jacira dos Santos Oliveira' } \\ \text { ORCID: 0000-0002-3863-3917 } \\ \text { Marta Miriam Lopes Costa' } \\ \text { ORCID: 0000-0002-2119-3935 } \\ \hline\end{array}$

Universidade Federal da Paraíba. João Pessoa, Paraíba, Brazil. "Universidade Federal de Campina Grande. Campina Grande, Paraíba, Brazil.

How to cite this article: Cruz RAO, Filgueiras TF, Pereira MA, Agra G, Oliveira JS, Costa MML. Construction validation of an instrument for nursing care related to cutaneous xerosis.

Rev Bras Enferm. 2020;73(Suppl 3):e20190777. doi: http://dx.doi.org/10.1590/0034-7167-2019-0777

Corresponding author: Ronny Anderson de Oliveira Cruz E-mail: ronnyufpb@gmail.com

EDITOR IN CHIEF: Antonio José de Almeida Filho ASSOCIATE EDITOR: Hugo Fernandes

Submission: $20-01-2020$

Approval: 04-05-2020

\section{ABSTRACT}

Objective: Describe the construct validation process of the instrument "Nursing care for the assessment, prevention and treatment of cutaneous xerosis in the elderly". Method: Methodological study carried out with 101 nurses in four hospitals in the great João Pessoa, between July and September 2018. Construct validation was performed through exploratory and confirmatory factor analysis, in addition to the consistency check by Cronbach's alpha. Results: Through the factorial analysis, three factors of the instrument construct were defined: treatment performed for cutaneous xerosis, preventive care for cutaneous xerosis and skin evaluation, with a total explanation variance of $47.77 \%$. In Bartlett's sphericity test, $p<0.001$ was obtained, and the general Cronbach's alpha was 0.811 . Conclusion: The instrument proved to be valid and reliable, contributing to the training and practice of nurses as an integral part in the process of caring for the elderly.

Descriptors: Nursing; Validation Studies; Skin aging; Nursing care; Health of the Elderly.

\section{RESUMO}

Objetivo: Descrever o processo de validação de constructo do instrumento "Cuidados de enfermagem para avaliação, prevenção e tratamento da xerose cutânea em pessoas idosas". Método: Estudo metodológico realizado com 101 enfermeiros em quatro hospitais da grande João Pessoa, entre julho e setembro de 2018. Realizou-se a validação de constructo por meio da análise fatorial exploratória e confirmatória, além da verificação da consistência pelo alfa de Cronbach. Resultados: Mediante a realização da análise fatorial, foram definidos três fatores do constructo do instrumento: tratamento realizado para a xerose cutânea, cuidados preventivos para a xerose cutânea e avaliação da pele, com variância total de explicação de $47,77 \%$. No teste de esfericidade de Bartlett, obteve-se $p<0,001$, e o alfa de Cronbach geral foi de 0,811. Conclusão: $\mathrm{O}$ instrumento mostrou-se válido e confiável contribuindo para a formação e prática dos enfermeiros como parte integrante no processo do cuidar de pessoas idosas. Descritores: Enfermagem; Estudos de Validação; Envelhecimento da Pele; Cuidados de Enfermagem; Saúde do Idoso.

\section{RESUMEN}

Objetivo: Describir el proceso de validación de constructo del instrumento "Cuidados de enfermería para evaluación, prevención y tratamiento de la xerosis cutánea en personas ancianas". Método: Estudio metodológico realizado con 101 enfermeros en cuatro hospitales de la grande João Pessoa, entre julio y septiembre de 2018. Se ha realizado la validación de constructo por medio del análisis factorial exploratorio y confirmatorio, además la verificación de la consistencia por el alfa de Cronbach. Resultados: Mediante la realización del análisis factorial, han sido definidos tres factores del constructo del instrumento: tratamiento realizado para la xerosis cutánea, cuidados preventivos para la xerosis cutánea y evaluación de la piel, con desviación total de explicación de 47,77\%. En el test de esfericidad de Bartlett, se obtuvo $p<0,001$, y el alfa de Cronbach general ha sido de 0,811. Conclusión: El instrumento se mostró válido y confiable contribuyendo para la formación y práctica de los enfermeros como parte integrante en el proceso del cuidar de personas ancianas.

Descriptores: Enfermería; Estudios de Validación; Envejecimiento de la Piel; Cuidados de Enfermería; Salud del Anciano. 


\section{INTRODUCTION}

The desire to increase life expectancy has always been a desire present in different societies, and the change in the age pyramid has already shown that there is an increase, in absolute and relative terms, in the number of elderly people. Both in Brazil and in other countries, implications have been observed that go beyond changes in the demographic picture - for example, important changes in the epidemiological panorama, particularly due to the exponential increase in Chronic Non-communicable Diseases (CNCDs) $)^{(1)}$.

Cutaneous xerosis presents itself as a modification of the stratum corneum characterized by impaired proliferation and differentiation of keratinocytes, lipid content, hydration, $\mathrm{pH}$ and sebum production. Thus, it affects the skin barrier function and results in skin discomfort and aesthetic concerns, and the treatment is usually topical and symptomatic with emollients or keratolytics(2).

In elderly people, xerosis results from a decrease in the hydration of the skin surface and the consequent increase in trans-epidermal water loss. The water content and the protection of its barrier function are essential factors for the health and maintenance of the appearance of the skin. In these cases, the most affected layer is the outermost layer of the epidermis, the stratum corneum, composed of corneocytes, a lipid bilayer, and its natural hydration factors, which, when working in harmony, guarantee the integrity and hydration of the skin. Commonly treated as senile xerosis, it is one of the most prevalent dermatological problems, affecting about $30 \%$ to $58 \%$ of elderly people ${ }^{(3-4)}$.

The assessment, prevention and treatment of conditions inherent to skin integrity are almost exclusive responsibilities of nursing, therefore knowledge about risk factors, physiology, anatomy, stages of the healing process and peculiarities of each stage of life become essential. This knowledge leads to a diagnosis of the type of injury and indication of appropriate technologies for prevention and treatment. It should be noted that injury prevention and treatment are dynamic processes and must accompany scientific and technological developments ${ }^{(5)}$.

Thus, nurses find in the Nursing Process (NP) the methodological path that makes it possible to identify, monitor, understand, describe and explain the needs of a person, the family or even the human community as it guides, directs and organizes professional care. To provide scientific support, it is anchored in a theoretical model and, in Brazil, the most used has been the Theory of Basic Human Needs (TBHN), by Horta, which guides nursing care at the psychobiological, psychosocial and psycho-spiritual levels ${ }^{(6)}$.

Based on the Basic Human Needs (BHN) worked by Maslow in the Theory of Human Motivation, Horta developed his theoretical model, which encompasses three general principles: the law of holism, according to which the whole is not simply the sum of the parts, but the set from them; the law of balance (homeostasis), which defines that the entire universe is maintained by processes of dynamic balance between individuals; and, finally, the law of adaptation, in which individuals try to remain in balance by interacting with their external environment ${ }^{(7)}$.

When performing the NP, nurses define the diagnoses, results and interventions that will present greater resolution and better quality. From this perspective, it is necessary to build valid and reliable instruments for the execution of care, as well as the development of research in order to measure certain phenomena in the health area. The measurement of a construct should be performed with instruments that have characteristics of validity, reliability and reliability, as well as being considered stable and with good internal agreement. Thus, the need to evaluate constructs allows improvements with regard to assistance and leads Nursing to appropriate the principles of psychometry for the elaboration, adaptation and validation of instruments ${ }^{(8)}$.

Researchers have warned of the need for an in-depth assessment of the measurement properties of questionnaires. It is necessary to remain attentive to the choice of an adequate and precise instrument, in order to guarantee the quality of its results and detailed understanding of the items, domains, forms of evaluation and, especially, measurement properties before use ${ }^{(9)}$.

There is a lack of measurement tools validated in the literature for nursing care aimed at the elderly's skin.

\section{OBJECTIVE}

Describe the construct validation process of the instrument "Nursing care for the assessment, prevention and treatment of cutaneous xerosis in the elderly".

\section{METHOD}

\section{Ethical aspects}

Ethical aspects were ensured in accordance with the recommendations of Resolution 466/2012 $2^{(10)}$ of the National Health Council, with approval by the Research Ethics Committee of the Health Sciences Center of the Federal University of Paraíba.

\section{Design, study location and period}

This is a methodological study for the construct validation of an instrument for the assessment, prevention and treatment of cutaneous xerosis in the elderly. It was carried out in two stages, the first of which was based on the content validation carried out by five judges, in order to identify items that might not be adequate to the objectives proposed in the research. Then, the instrument was applied to nurses from four hospitals in the great João Pessoa-PB in the three shifts, between the months of July and September 2018.

\section{Sample, inclusion and exclusion criteria}

The non-probabilistic and convenience sampling technique was used. Before the collection, the research objectives were explained to the nurses, the right to anonymity, confidentiality and the possibility of giving up at any time; and, finally, it was requested to sign the Free and Informed Consent Term (FICF). A total of 101 nurses from a population of 120 active in the sectors of Internal Medicine and Intensive Care Unit of the adult participated. Salienta-se que as quatro instituições hospitalares têm o caráter de hospital-escola.

Regarding the sample size, it should be noted that a researcher hardly performs a factor analysis with a sample of less than 50 observations; in this sense, Hair ${ }^{(11)}$ advises that, preferably, the sample contemplates a value greater than or equal to 100 . Inclusion criteria for participation in the research were considered: being a 
nurse who worked in units as assistance, being active during the data collection period, as well as performing the Nursing Care Systematization (NCS). Nurses who worked only in administrative functions, were away on leave or vacation or refused to participate in the study during the data collection phase were excluded.

\section{Study protocol}

The collection instrument was composed of two parts: the first, with information about sociodemographic data; and the second, initially composed of 32 items, however, after the content validation stage, it now has 34. The content validation was performed based on the calculation of the Content Validity Coefficient (CVC). This evaluates the level of agreement taking into account four criteria: clarity of language, practical relevance, theoretical relevance and dimension. After calculating the average of each judge, the CVC was calculated, in which items with CVC values $>0.8$ were considered acceptable ${ }^{(12)}$. Therefore, a factor analysis was performed to describe the psychometric properties related to the construct validity and reliability.

The items were divided into three domains, namely: 1 - Evaluation of the elderly person's skin; 2 - Products used for the prevention and treatment of cutaneous xerosis; and 3 - Nursing care prescribed in the presence of the Nursing Diagnosis of Impaired Skin Integrity related to cutaneous xerosis. The questions were classified according to a 5-point Likert scale, ranging from 1 (never), 2 (almost never), 3 (sometimes), 4 (almost always) to 5 (always). And for domain 3, ranging from 1 (never prescribe or never perform), 2 (almost never prescribe or almost never perform), 3 (sometimes prescribe or sometimes perform), 4 (almost always prescribe or almost always perform) and 5 (always prescribe or always do).

The stages determined by Pasquali $(2010)^{(12)}$, for which the instrument, to have good psychometric qualities, must respect the following precepts: excellent bibliographic support, providing the instrument with a consistent theoretical basis that justifies its quality; define a system to be evaluated, its properties and attributes (if seen in the theoretical review, define if there are one or more dimensions and, for each one, the constitutive and operational definitions). For operationalization: build clear, understandable items that respect the presented theory; perform the theoretical and semantic analysis of the items through the validation of the expert judges; apply the instrument systematically. After collection, it is necessary to perform statistical analysis of the data to verify the dimensionality and the indices related to factors, such as: factor load, eigenvalue and commonality and to verify the internal consistency of the instrument using the Cronbach alpha precision index.

\section{Analysis of results}

After applying the instrument to 101 nurses, the statistical software Statistical Package for the Social Sciences, version 25.0, was used for data processing. Statistical analyzes of distribution and frequency were performed to characterize the sample, in addition to the chi-square test in order to assess the association between the choice of items and whether or not courses in the area of prevention and treatment of skin injuries.

Aiming to validate the instrument's construct, Exploratory Factor Analysis (EFA) was performed, using the factorization model of the main axis; and Confirmatory Factor Analysis (CFA). EFA consists of a technique within factor analysis whose objective is to identify the underlying relationships between the variables measured. Thus, it allows the correlations present in a large number of variables to be grouped into factors, allowing the recognition of the most representative ones or creating a new set of variables, much smaller than the original. When performing the factorization model of the main axis, the square of the multiple correlations is used as an estimate of the communalities, represented by the proportion of the variance of a variable that is shared with the common factors in the factor analysis. The communalities are placed diagonally from the main matrix, before the extraction of the factors ${ }^{(13)}$.

Therefore, CFA is used to test hypotheses. So, the researcher is allowed, based on some theory, to test the extent to which certain variables are representative of a concept or dimension ${ }^{(14)}$.

In order to assess reliability, Cronbach's alpha test was performed, which is calculated by the variance of the individual items and variance of the sum of the items of each appraiser, where the result must be positive, ranging from 0 to 1 , and categorized as follows: above 0.8 , it is excellent; greater than 0.7 , is considered to be good; and less than 0.4 , is bad $^{(15)}$.

In order to carry out the analysis of the adequacy of the sample for the performance of the EFA, the Kaiser-Meyer-Olkin test (KMO) was applied, which both represents the proportion of the variance that the variables as a whole present in common, as well as values between 0 and 1 are expected, it considers that those below 0.5 make the analysis. Then, the analysis of the anti-image matrix was performed, in which its diagonal reveals normal values between 0.5 and 1, indicating the degree of adjustment of each variable to the factor analysis. When analyzing the correlation matrix, the possibility of being feasible is verified by verifying the statistical distribution of the chi-square using Bartlett's sphericity test, which has the purpose of refuting the hypothesis that the correlation matrix is an identity matrix (presents the value on the diagonal corresponding to 1 , and the others equal to 0 ), whose result shows significance when the value is less than $0.05^{(16)}$.

The last observation to be made before proceeding to the analysis is the Sampling Suitability Measure (SSM) per item, in which they need to score at least 0.500 to remain in the analysis ${ }^{(11)}$. This measure is calculated by the equation:

$$
K M O=\frac{\sum \sum_{j \neq k} r_{j k}^{2}}{\sum \sum_{j \neq k} r_{j k}^{2}+\sum \sum_{j \neq k} q_{j k}^{2}}
$$

The factorial loads represent the correlation between the indicator and the extracted factor, in which the values between 0.30 and 0.40 are considered minimum, 0.50 and 0.70 are significant and greater than 0.70 are indicative of a well-defined structure ${ }^{(14)}$.

\section{RESULTS}

The instrument was built by conducting an integrative review of the literature on the subject, as well as by searching books that dealt with the process of caring for the skin of elderly people. 
The content validation took place through five judges, PhDs in nursing, with expertise in the area of adult and elderly health, average age of 48 years and average professional practice time equal to 26 years. Such validation was carried out with the purpose of identifying items that might not be adequate and, in the meantime, allowed to ascertain the level of agreement based on the aspects of language clarity, practical relevance, theoretical relevance and dimension, with a general CVC $=0.82$, according to the results presented in Chart 1.

Among the nurses participating in the study, there was a predominance of females (84.2\%), with a mean age of 36.51 (SD =7.67; minimum $=24$; maximum $=62$ ). Participants' working time averaged 9.33 years ( $S D=7.99$; minimum $=6$ months; maximum $=35$ years), and it was observed that the majority had the title of specialists (59.4\%), followed by graduates (32.7\%), masters (5.9\%) and only two doctors (2\%).

With regard to years of experience with the $\mathrm{NP}$, there was an average of 7.48 years (SD = 6.25; minimum $=0.6$; maximum $=35$ ). It was found that 65 nurses (64.4\%) had no course in the area of prevention and / or treatment of skin lesions. As for the number of employment relationships, most subjects indicated working in more than one job (60.4\%); and, of these, 52 (85.2\%) reported working with two jobs. The weekly shift varied between 20 and 74 hours, with an average of 42.63 hours (SD $=12.8$ ).

The KMO measure of sampling adequacy was considered satisfactory, with $\mathrm{KMO}=0.707$ (values must be between 0.5 and 1); Bartlett's sphericity test refuted the hypothesis of an identity matrix with $\left[x^{2}(253)=1044.924 ; p<0.001\right]$, where the result must be less than 0.05 . With regard to the SSM to remain in the analyzes, items $1,2,4,6,7,11,12,13,16,21$ and 31 needed to be removed so that the EFA could be continued, as shown in Table 1.

The Scree Plot graph, seen in Figure 1, indicates the existence of three factors and shows that the number of factors is defined by the cutoff point that points to the moment at which the single variance becomes shared.

After the item removal procedure, a new EFA was performed, which generated the results shown in Table 2, allowing the conclusion that the factors had excellent eigenvalues and a good explained variance.

Factor 1 has ten items, with factor loads between 0.308 and 0.832 , while Factor 2 extracted seven items with factor loads between 0.345 and 0.852 , and Factor 3 got six items whose factorial loads fluctuated between 0.296 and 0.742 . A Figura 2 mostra a estrutura fatorial apontada como possível após EFA.

CFA was carried out; however, due to the quantity of the sample, confirmation was not possible since the cutoff points indicated by Hair ${ }^{(11)}$ for RMSEA indices they must be less than 0.08 (RMSEA $=0.187$ ) and, for PGFI, NFI and CFI, they must be greater than 0.90 , but they were not.
Chart 1 - Distribution of Content Validity Coefficient values of the items of the instrument "Nursing care for the assessment, prevention and treatment of cutaneous xerosis in elderly people", João Pessoa, Paraíba, Brazil, 2018

\begin{tabular}{|l|l|}
\hline Item & CVC \\
\hline 1. It is important to consider the age group. & 0.913 \\
\hline 2. I evaluate the skin color. & 0.979 \\
\hline 3. I evaluate the turgor and the elasticity of the skin. & 0.813 \\
\hline 4. I observe the patient's temperature. & 0.846 \\
\hline 5. I don't consider excess moisture. & 0.813 \\
\hline 6. I look for cracks. & 0.813 \\
\hline 7. I notice skin lesions. & 0.916 \\
\hline 8. I observe the presence of flaking. & 0.946 \\
\hline 9. I notice the presence of itching. & 0.896 \\
\hline 10. I keep an eye out for cold exposure. & 0.913 \\
\hline 11. I use imported equipment that assesses skin hydration. & 0.810 \\
\hline 12. To choose the type of moisturizer I do not consider skin evaluation. & 0.814 \\
\hline 13. I use products based on essential fatty acids. & 0.996 \\
\hline 14. I use 10\% or 20\% urea creams. & 0.996 \\
\hline 15. I use barrier cream. & 0.846 \\
\hline 16. Use any moisturizer that is available. & 0.929 \\
\hline 17. I apply formulations based on aloe vera. & 0.846 \\
\hline 18. I use medium chain triglyceride formulations. & 0.829 \\
\hline 19. I apply mineral oil. & 0.946 \\
\hline 20. Inspect skin conditions daily. & 0.946 \\
\hline 21. Record the findings about the patient's skin. & 0.946 \\
\hline 22. Identify patients at risk for skin lesions due to dryness. & 0.841 \\
\hline 23. Hydrate the skin with the right products. & 0.996 \\
\hline 24. Be aware of maceration areas. & 0.841 \\
\hline 25. Be aware of areas of hyperemia. & 0.916 \\
\hline 26. Carefully evaluate the lower limbs, especially the interdigital spaces. & 0.996 \\
\hline 27. Provide body hygiene whenever necessary. & 0.913 \\
\hline 28. Provide intimate hygiene whenever necessary. & 0.946 \\
\hline 29. Remove residues adhered to the skin from fixatives. & 0.813 \\
\hline 30. Discuss with the nursing team the need to increase oral or parenteral hydration. & 0.907 \\
\hline 31. Guide family members about signs of the patient's skin dryness. & 0.996 \\
\hline 32. Guide the nursing team in relation to water temperature. & 0.946 \\
\hline 33. Guide the nursing team regarding the use of the appropriate soap. & 0.946 \\
\hline 34. Guidance for self-care. & 0.979 \\
\hline Note: CVC - Content Validity Coefficient. & \\
\hline
\end{tabular}

Table 1 - Adequacy measure of sampling by item, João Pessoa, Paraíba, Brazil, 2018

\begin{tabular}{ll}
\hline Item & MAA \\
\hline 1. It is important to consider the age group. & 0.341 \\
2. I evaluate the skin color. & 0.402 \\
3. I evaluate the turgor and the elasticity of the skin. & 0.517 \\
4. I observe the patient's temperature. & 0.307 \\
5. I don't consider excess moisture. & 0.545 \\
6. I look for cracks. & 0.451 \\
7. I notice skin lesions. & 0.380 \\
8. I observe the presence of flaking. & 0.517 \\
9. I notice the presence of itching. & 0.517 \\
10. Stay tuned for cold exposure. & 0.511 \\
11. I use imported equipment that assesses skin hydration. & 0.450 \\
12. To choose the type of moisturizer, I do not consider skin & 0.304 \\
evaluation. & \\
13. I use products based on essential fatty acids. & 0.387 \\
14. I use 10\% or 20\% urea creams. & 0.750 \\
15. I use barrier cream. & 0.576 \\
16. Use any moisturizer that is available. & 0.398 \\
17. I apply formulations based on aloe vera. & 0.692 \\
18. I use medium chain triglyceride formulations. & 0.763 \\
19. I apply mineral oil. & 0.633 \\
20. Inspect skin conditions daily. & 0.589 \\
21. Record the findings about the patient's skin. & 0.491 \\
\hline
\end{tabular}


Table 1 (concluded)

\begin{tabular}{lc} 
Item & MAA \\
\hline 22. Identify patients at risk for skin lesions due to dryness. & 0.527 \\
23. Hydrate the skin with the right products. & 0.683 \\
24. Be aware of maceration areas. & 0.534 \\
25. Be aware of areas of hyperemia. & 0.633 \\
26. Carefully evaluate the lower limbs, especially the interdigital & 0.667 \\
spaces. & \\
27. Provide body hygiene whenever necessary. & 0.659 \\
28. Provide intimate hygiene whenever necessary. & 0.589 \\
29. Remove residues adhered to the skin from fixatives. & 0.588 \\
30. Discuss with the nursing team the need to increase oral or & 0.695 \\
parenteral hydration. & \\
31. Guide family members about signs of the patient's skin dryness. & 0.474 \\
32. Guide the nursing team in relation to water temperature. & 0.620 \\
33. Guide the nursing team regarding the use of the & 0.593 \\
appropriate soap. & \\
34. Guide for self-care. & 0.657
\end{tabular}

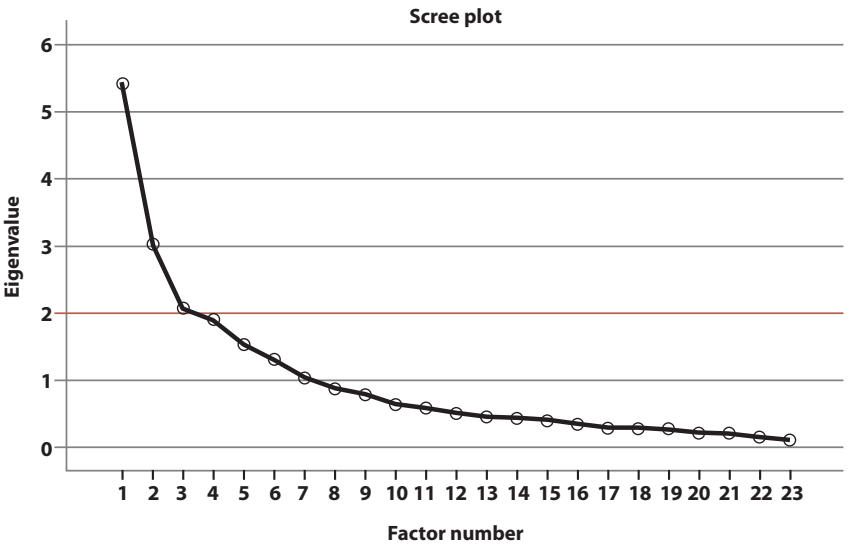

Figure 1 - Scree Plot graph, João Pessoa, Paraíba, Brazil, 2018

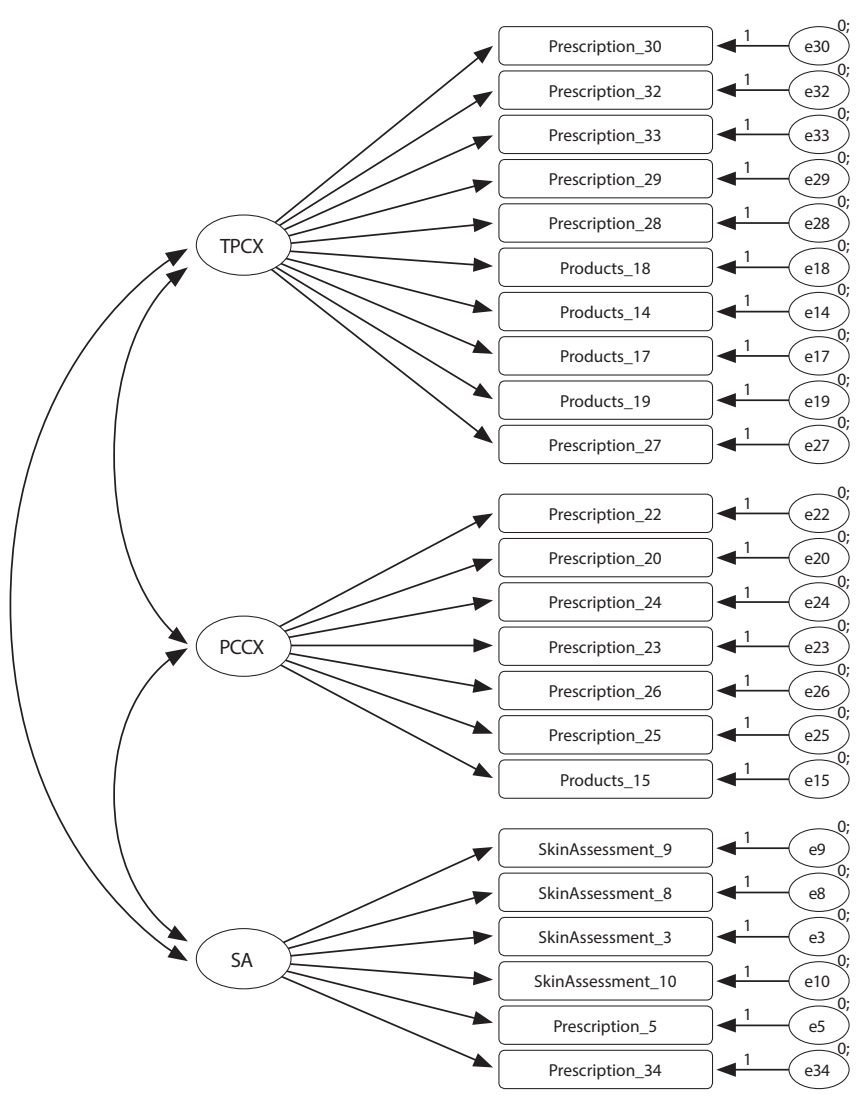

Figure 2 - Path diagram for the instrument "Nursing care for the assessment, prevention and treatment of cutaneous xerosis in elderly people", João Pessoa, Paraíba, Brazil, 2018

Table 2 - Distribution of factor loads, eigenvalues, explained variance and Cronbach's alpha of the instrument "Nursing care for the assessment, prevention and treatment of cutaneous xerosis in elderly people", João Pessoa, Paraíba, Brazil, 2018

\begin{tabular}{|c|c|c|c|}
\hline Items & F1 & F2 & F3 \\
\hline 30. Discuss with the nursing team the need to increase oral or parenteral hydration. & 0.832 & & \\
\hline 27. Guide the nursing team in relation to water temperature. & 0.808 & & \\
\hline 28. Guide the nursing team regarding the use of the appropriate soap. & 0.686 & & \\
\hline 29. Remove residues adhered to the skin from fixatives. & 0.631 & & \\
\hline 28. Provide intimate hygiene whenever necessary. & 0.554 & & \\
\hline 18. I use medium chain triglyceride formulations. & 0.527 & & \\
\hline 14. I use $10 \%$ or $20 \%$ urea creams. & 0.524 & & \\
\hline 17. I apply formulations based on aloe vera. & 0.443 & & \\
\hline 19. I apply mineral oil. & 0.404 & & \\
\hline 27. Provide body hygiene whenever necessary. & 0.308 & & \\
\hline 22. Identify patients at risk for skin lesions due to dryness. & & 0.852 & \\
\hline 20. Inspect skin conditions daily. & & 0.679 & \\
\hline 24. Be aware of maceration areas. & & 0.665 & \\
\hline 23. Hydrate the skin with the right products & & 0.624 & \\
\hline 26. Carefully evaluate the lower limbs, especially the interdigital spaces.. & & 0.554 & \\
\hline 25. Be aware of areas of hyperemia. & & 0.545 & \\
\hline 15. I use barrier cream. & & 0.345 & \\
\hline 9. I notice the presence of itching. & & & 0.742 \\
\hline 8. I observe the presence of flaking. & & & 0.632 \\
\hline 3. I evaluate the turgor and the elasticity of the skin. & & & 0.446 \\
\hline 10. Stay tuned for cold exposure. & & & 0.426 \\
\hline 5. I don't consider excess moisture*. & & & -0.367 \\
\hline 34. Guide for self-care. & & & 0.296 \\
\hline Self-values & 5.42 & 3.02 & 2.08 \\
\hline Variance explained by factor & $25.57 \%$ & $13.16 \%$ & $9.04 \%$ \\
\hline Variance Explained Total & $47.77 \%$ & & \\
\hline Cronbach's alpha & 0.83 & 0.81 & 0.61 \\
\hline
\end{tabular}

Note: *Item 5 is a negative statement, and the score achieved depicts exactly the opposite. 


\section{DISCUSSION}

It is pertinent to understand the need for improvements in the quality of care and, with that, in nursing care. For this, the NP based on a nursing theory represents a scientific and methodological model that allows, through its implementation through stages, to guide nurses in their actions. This gives them flexibility, information and scientific support on the care provided, especially based on the Standardized Language Systems such as the NANDA-I Nursing Diagnosis Classification, the Nursing Interventions Classification(NIC) and Nursing Outcomes Classification(NOC), providing a clear and coherent language that facilitates communication, intervention and evaluation of expected results ${ }^{(17)}$.

The xerotic condition of the skin in the elderly person increases the vulnerability to the appearance of lesions, due to the decrease of nonspecific defense, contributing to the risk of opportunistic infections. With the decrease in elasticity, less resistance to mechanical movement occurs, in addition to the propagation of a double path cycle in which, the drier the skin, the greater the loss of trans-epidermal water and vice versa ${ }^{(18)}$.

In this sense, the construct validity of an instrument allows for generating predictions based on the construction of hypotheses, and these predictions are tested to support the validity of the instrument, so that the more abstract the concept, the more difficult it is to establish the validity of construct. It should be noted that this result is hardly achieved in a single study. In this perspective, we opted for factor analysis that provides tools to assess the correlations in a large number of variables defining the factors, that is, the variables strongly related to each other ${ }^{(9)}$.

With a result of the sample adequacy test $\mathrm{KMO}=0.707$, it was observed that the results are adequate and amenable to generalization, considering that a value greater than 0.5 is considered. Regarding Bartlett's sphericity test, a result less than 0.05 is necessary ${ }^{(19)}$, which was achieved, as well as when assessing the SSM, whose items need to score at least 0.500, which led to the removal of 11 items from the questionnaire on screen.

Their departure may be related to the fact that $64.4 \%$ of nurses do not have courses in the area of prevention or treatment of skin lesions. Thus, one of the crucial aspects in the face of the constant changes in the current world is the need to invest in professional training. In the context of health, education through work has been considered an instrument for changes and transformations, pointing out alternatives in ways of producing quality health and greater satisfaction of users and professionals ${ }^{(20)}$.

Regarding the values of the factorial loads, it is known that when they are between 0.30 and 0.40 , they are considered as minimum, however, due to their importance, one chose to keep items 15, 27 and 34, which are respectively: make use of barrier cream; provide body hygiene whenever necessary; and guide for self-care.

The moments dedicated to hygiene care are usually valued by elderly patients. A study carried out in Lisbon revealed that, in addition to hygiene, such care refers to the image of a body free of pathogenic microorganisms, which contributed to the feeling of relief and lightness, improving the state of comfort. It is an act in which there is an interrelation between those who care and those who are cared for ${ }^{(21)}$.
Regarding the barrier cream, it consists of a water-repellent product that stabilizes the skin's pH and protects against body fluids (urinary and intestinal effluents); in perilesional areas it acts against wound fluids, however it should not be used on mucous membranes or areas with broken skin ${ }^{(22)}$.

Another study carried out with 250 elderly people monitored by Primary Health Care Units (PHCU) found that the practice of self-care in relation to the skin has weaknesses and that it is directly linked to a cultural process of health knowledge and its relationship with education in health. In this context, there is a need to build a dialogic and shared process permeated by an interrelation between common sense knowledge and scientific technical knowledge ${ }^{(23)}$.

The general Cronbach's alpha coefficient was 0.811 , with 0.83 for factor 1, 0.81 for factor 2 and finally factor 3 with 0.61 . It is noteworthy that factor 3 , for having the lowest number of items, obtained the lowest alpha, however this does not invalidate the analysis.

In the analysis of the main components of this instrument, the results of the eigenvalues were also observed, which must be greater than $1^{(24)}, 5.42$ for $\mathrm{F} 1 ; 3.02$ for $\mathrm{F} 2$; and 2.08 for $\mathrm{F} 3$ - in addition to a variance explained by factor with values of $25.57 \%, 13.16 \%$ and $9.04 \%$, respectively, and a total explained variance of $47.77 \%$.

Generally, there is a scarce literature on instruments that specifically contemplate the skin evaluation of the elderly in Brazil, however, a methodological study proposed the assessment of skin turgor and the consequent state of skin hydration in the elderly, using an instrument called the Skin Turgor Assessment Scale (STAS). The assessment is carried out as follows: after physical examination and skin type determination, STAS is applied, which, by describing the condition of the skin and the respective scores, quantifies the degree of dehydration. STAS is simple, easy, quick to apply and can facilitate the work of nurses in the search for individualized injury prevention ${ }^{(25)}$.

After the performance of the EFA, it was decided to rename the dimensions in order to clarify the understanding about the items that remained in each factor. Thus, dimension 1 entitled "Evaluation of the skin of the elderly" became "Treatment performed for cutaneous xerosis"; dimension 2 entitled "Products used for the prevention and treatment of cutaneous xerosis" became"Preventive care for cutaneous xerosis". Finally, dimension 3 entitled "Nursing care prescribed in the presence of the Nursing Diagnosis impaired skin integrity related to cutaneous xerosis" became "Skin assessment".

\section{Study limitations}

The study's limitation is in the fact that it was necessary to remove 11 items to perform the EFA, however they were considered relevant during content validation made by the judges when considering the following criteria: clarity of language, practical relevance, theoretical relevance and dimension. Thus, to confirm the presence of the items and perform the CFA, it is necessary to continue the study with the application of the instrument with suggested $n$-sample: $>$ / = 300 subjects.

\section{Contributions to the area of Nursing, Health or Public Policy}

The study presents contributions to the area of Nursing, Health or Public Policy, since the built and validated instrument that was 
developed can contribute as a tool capable of directing thinking and doing about nursing care for evaluation, prevention and treatment of cutaneous xerosis in elderly people, in addition to contributing to the conduct of future research and the creation of protocols on the subject. Still, it brought as a theoretical-conceptual basis the Theory of Basic Human Needs, from Horta, in addition to the valorization of the Nursing Process as a working method.

\section{CONCLUSION}

The results of this study show that the instrument "Nursing care for the assessment, prevention and treatment of cutaneous xerosis in elderly people" proved to be valid and reliable, contributing to the practice of nurses as an integral part in the process of caring for the elderly as well as an instrument for conducting research on the subject.

The Theory of Basic Human Needs, from Horta, was presented as a theoretical-conceptual basis, being possible to add the care presented here when considering the need for hydration inherent to the set of psychobiological needs.

The evaluation of the use of this instrument in practice and the need for possible adjustments with a view to improvements will occur through the application to more subjects, which will enable the performance of its confirmatory factor analysis.

\section{REFERENCES}

1. Dantas IC, Pinto Jr EPP, Medeiros KKAS, Souza, EE. Perfil de morbimortalidade e os desafios para a atenção domiciliar do idoso brasileiro. Rev Kairó. 2017;20(1):93-108. doi: 10.23925/2176-901X.2017v20i1p93-108

2. Boralevi F, N'Djong AM, Yoboue PY, Faye O, Dieng MT, Coniquet S, et al. Regression of cutaneous xerosis with emollient treatment in subSaharan African patients. Int J Dermatol[Internet]. 2017 [cited 2018 Nov 26];56(4):467-73. Available from: https://www.ncbi.nlm.nih.gov/ pubmed/28205205

3. Bagherani N. The efficacy of bed bath together with heparinoid containing moisturizers in treating senile xerosis. Dermatol Ther[Internet]. 2016 [cited 2018 Nov 28];29(1):69. Available from: https://www.ncbi.nlm.nih.gov/pubmed/26087844

4. Melo MA, Campos PMBGM. Técnicas para avaliar a hidratação e a oleosidade da pele. Cosmet Toiletries[Internet]. 2016 [cited 2018 Nov 28];28(2):30-4. Available from: http://www.cosmeticsonline.com.br/ct/painel/class/artigos/uploads/0b33c-282_EdMar_Abr-2016.pdf

5. Mittag BF, Krause TCC, Roehrs H, Meier MJ, Danski MTR. Cuidados com lesão de pele: ações da enfermagem. Rev Estima[Internet]. 2017 [cited 2018 Nov 28];15(1):19-25. Available from: https://www.researchgate.net/publication/314145321_Cuidados_com_Lesao_de_Pele_Acoes_da_Enfermagem/ download

6. Marques DKA, Silva KL, Nóbrega MML. Hospitalized school children: proposition of a data collection instrument in light of Horta's theory. Rev Gaúcha Enferm. 2016;37(esp):e2016-0038. doi: 10.1590/1983-1447.2016.esp.2016-0038

7. Silveira RCP, Robazzi MLCC. Nursing assessment of adults and older adults and the basic human needs theory: a reflection. Rev Enferm UFPE[Internet]. 2014 [cited 2019 Feb 18];8(10):3525-32. Available from: https://periodicos.ufpe.br/revistas/revistaenfermagem/article/ viewFile/10085/10534

8. Oliveira F, Kuznier TP, Souza CC, Chianca TCM. Theoretical and methodological aspects for the cultural adaptation and validation of instruments in nursing. Texto Contexto Enferm. 2018;27(2):e4900016. doi: 10.1590/0104-070720180004900016

9. Souza AC, Alexandre NMC, Guirardello EB. Psychometric properties in instruments evaluation of reliability and validity. Epidemiol Serv Saúde [Internet]. 2017 [cited 2018 Nov 28];26(3):649-59. Available from: http://www.scielo.br/pdf/ress/v26n3/en_2237-9622-ress-26-03-00649.pdf

10. Ministério da Saúde (BR). Concelho Nacional de Saúde. Resolução n. 466 de 12 de dezembro de 2012. Dispõe sobre diretrizes e normas regulamentadoras de pesquisas envolvendo seres humanos [Internet]. Brasília (DF): Ministério da Saúde; 2012. [cited 2018 Dec 02]. Available from: http://conselho.saude.gov.br/resolucoes/2012/Reso466.pdf

11. Hair JF, Black WC, Babin BJ, Anderson RE, Tatham RL. Análise Multivariada de dados. 6. ed. Porto Alegre (RS): Bookman; 2009.

12. Pasquali L. Instrumentação psicológica: fundamentos e práticas. Porto Alegre (RS): Artmed; 2010.

13. Hongyu K. Análise Fatorial Exploratória: resumo teórico, aplicação e interpretação. E\&S - Engineering and Science; 2018;4(7):88-103. doi: 10.18607/ES201877599

14. Figueiredo Filho DB, Silva Jr JA. Visão além do alcance: uma introdução à análise fatorial. Opin Pública [Internet]. 2010 [cited 2018 Dec 22];16(1):160-85. Available from: http://www.scielo.br/pdf/op/v16n1/a07v16n1.pdf

15. Zambardi JMR, Lopes CT, Morais SCRV, Newhouse RP, Lopes JL, Barros ALBL. Cross-cultural adaptation to Brazil and reliability of Smoking Cessation Counseling. Acta Paul Enferm. 2019;32(3):290-297. doi: 10.1590/1982-0194201900040

16. Borba LO, Capistrano FC, Ferreira ACZ, Kalinke LP, Mantovani MF, Maftum MA. Adaptation and validation of the Measuring of Treatment Adherence for mental health. Rev Bras Enferm. 2018;71(Suppl 5):2243-50. doi: 10.1590/0034-7167-2017-0796

17. Oliveira VC, Rabelo CBM, Vieira CPB, Costa JP. Intervenções de enfermagem na prevenção de lesões por pressão: estudo descritivoexploratório. Rev Prev Infecç Saúde [Internet]. 2017 [cited 2019 feb 19];3(3):21-29. Available from: http://www.ojs.ufpi.br/index.php/nupcis/ article/view/6581

18. González CVS, Yamada BFA. A pele seca e sua vulnerabilidade para lesões. In: Yamada BFA. Pele: o manto protetor - Higiene e hidratação. São Paulo: Andreoli; 2015. P. 65-72. 
19. Brito MFSF, Borém LMA, Messias RB, Silveira MF, Souza AMV, Leite MTS, et al. Desenvolvimento e validação de instrumento de avaliação dos aspectos que influenciam a solicitação de exames. Cad Saúde Colet. 2018;26(3):308-17. doi: 10.1590/1414-462×201800030012.

20. Salum NC, Prado ML. Continuing education in the development of competences in nurses. Texto Contexto Enferm. 2014;23(2):301-8. doi: $10.1590 / 0104-070720140021600011$

21. Ribeiro PCPSV, Marques RMD, Ribeiro MP. Geriatric care: ways and means of providing comfort. Rev Bras Enferm. 2017;70(4):865-872. doi: 10.1590/0034-7167-2016-0636

22. Campos MGCA, Sousa ATO, Vasconcelos JMB, Lucena SAP, Gomes SKA. Feridas complexas e estomias: aspectos preventivos e manejo clínico. João Pessoa (PB): Ideia; 2016.

23. Garbaccio JL, Ferreira AD, Pereira ALGG. Conhecimento e prática referidos por idosos no autocuidado com a pele no Centro-Oeste de Minas Gerais. Rev Bras Geriatr Gerontol [Internet]. 2016 [cited 2018 Dec 23];19(1):45-56. Available from: http://www.scielo.br/pdf/rbgg/v19n1/ pt_1809-9823-rbgg-19-01-00045.pdf

24. Stacciarini TSG, Pace, AE. Confirmatory factor analysis of the Appraisal of Self-Care Agency Scale - Revised. Rev Latino-Am Enfermagem. 2017;25:25:e2856. doi: 10.1590/1518-8345.1378.2856

25. Giaretta VMA, Silva AMS, Renó ACM, Aguiar DAF, Arantes CMS, Posso MBS. Proposta de escala para avaliar o turgor da pele em idosos. Rev Ciên Saúde [Internet] 2016 [cited 2018 Dec 24];1(1):01-07. Available from: http://revistaeletronicafunvic.org/index.php/c14ffd10/article/view/7 